Fraser, A., Stewart, E., Jones, L. The importance of sociological approaches to the study of service change in healthcare. Sociology of Health and IIIness 2019: 41(7): 1215-1220 


\section{Editorial: The Importance of sociological approaches to the study of service change in healthcare}

\section{Alec Fraser, Ellen Stewart \& Lorelei Jones}

\section{Introduction}

Change is an enduring facet of health care policy and practice. Service change ranges from far reaching macro-level political reforms such as the Health and Social Care Act of 2012 in the UK, or the Patient Protection and Affordable care Act of 2010 in the US, to regional system-wide reorganisations such as the devolution of health and social care in the Greater Manchester region of England from 2014. It also comprises meso-level programmes of change in local health care services, which may generate national media interest out of proportion with their apparent national significance. Particularly when such changes highlight conflicting view points and concern over perceived 'down-grading' of services - the Kidderminster case from the 1990s being a particularly high-profile example of this in the UK - campaigns against change can capture a wider public imagination. Service change likewise encompasses quotidian, micro-level modifications in health care service provision-for example de-coupling or co-locating certain clinical services in new configurations - which can have profound consequences for particular populations of staff and service users. All such service change - from the large to the small scale - affects the social and spatial realities for multiple groups (patients, publics, and those employed by and within health care institutions). As the anthropologist Elisabeth Colson (1971) observed, large-scale 
change 'hurts' a fact largely ignored by planners and politicians concerned with the economic but not the social costs.

Agreeing terminology with respect to service change is problematic, and is itself a political act. There are multiple emic terms, reflecting the different analyses, interests, and meanings of different social groups, and the essentially rhetorical and discursive character of policy processes (Jones 2016). For example, while national policy texts often adopt rational, and politically neutral, terms such as 'reconfiguration', other actors, such as patient and community groups, are more likely to recognise the topic as plans to close local services. The emic terminology is not stable but rather changes over time. Whilst policy texts from the 1980s refer to 'rationalisation' (Pettigrew et al 1992), terms that are more recent include 'service change', 'system change', and 'transformation'. During the development of this special section, we found it difficult to decide what to call 'it', often switching back and forth between different terms. We wanted to choose a single term that could be used for the multiple descriptions and explanations of actors, without simply repeating the analysis of one particular group (Callon 1986) but with the topic still remaining recognizable to a range of audiences.

In this special section, we understand service change as a field of practice and a site of political contestation. We adopt the following definition: 
Policies, strategies or interventions that aim to transform the way multiple care services are coordinated at the inter-and intra-organisational level to address a single service areas (e.g. stroke) or integrated service domain (e.g. primary care).

Such service change is worthy of research for a number of reasons. Firstly, such change highlights the act of government as a 'problematizing activity' (Foucault, 2007; Dean, 2010) and opens new vistas for research to explore how multiple organisations construct and understand their own strengths and inadequacies (Legg, 2005). Secondly, it encourages clinicians, managers, policymakers and other interested actors to develop new techniques to challenge historical failings - this makes the reformed organisational strategies 'visible' to the outside gaze (Dean, 2010). Thirdly, service change takes place within a milieu of public contestation and conflicting political discourses which adds to the complexity of this form of decision-making (Jones \& Exworthy, 2015; Stewart, 2016).

Despite such promise, an enduring criticism of existing research into service change is that it is conceptually under-developed (Fulop et al, 2012). As Jones et al (this collection) demonstrate, much (but not all) research in this field has also tended to be highly normative and reinforcing of dominant policy arguments. Key sociological concerns such as the importance of power, relationships, the multiplicity of views and voices are all too often obscured by research that uncritically explores 'barriers' and 'facilitators' to implementation of change through evaluations that are normatively driven. Likewise, the importance of ethnographic methods and causal theory is marginalised in much existing research into service change. 
The aim of this special section is to collate a small collection of papers that explicitly and thoughtfully challenge the taken for granted nature of service change - in particular, some of the dominant technicist and managerial discourses prevalent in existing work in this area. Through doing so, these papers highlight the contribution that sociology can make to a more critical and pluralist understanding of service change. Our aim is for such critique to be productive and transformative - the section seeks to offer alternative perspectives on service change alongside analysis of those that already exist (Lemke, 2011). Neither 'critical outsiders' nor 'enthusiastic insiders' our aim is to articulate new agendas, and more and different features of the healthcare system than those found in dominant accounts (Jensen 2008). We briefly introduce the four papers that make up the special section next before offering some thoughts on the emergent themes that the papers raise and offering some final reflections at the end of this article.

\section{Papers included in this special section}

The special section consists of four articles produced by UK based researchers which offer new empirical and conceptual insights about major service change. The first paper reviews the literature on large scale change in healthcare and therefore takes in a broad selection of papers from multiple international jurisdictions - yet English NHS studies dominate (17/33). The other three articles report empirical findings from one English NHS study, and two from Scottish NHS cases. The review article (Jones et al) takes a multi-level overview approach as might be anticipated. The English case (Lorne et al) takes a macro-/meso-level approach to large scale service change in Greater Manchester. Stewart explores meso-level service 
change across three hospitals in Scotland, and Wright explores service change at the microlevel though a study of a newly integrated sexual and reproductive healthcare facility - once more in Scotland. Despite the Anglo-Scottish dominance, a great strength of this collection is the diversity in spatial foci of the articles. In contrast to the majority of research in this area, these papers explicitly explore the social practices involved in the 'un-making' and 'remaking' of space in understandings of what hospitals, health services and even wider regions 'mean'. In the presentation of these papers, we will work from the macro- right through to the micro-level.

This prompts us to begin with Jones et al's 'Exploring the neglected and hidden dimensions of large-scale healthcare change'. The authors present a narrative literature review of studies of major service change published in the English language over the past three decades. In theoretical terms, the authors challenge the normative, sometimes poorly conceptualised 'technicist' domination of the field as rendered by many evaluative studies identified in the review. However, they helpfully identify sociologically informed work in this space that employs Critical, Foucauldian, and Institutional theories alongside politically informed approaches to the study of major service change thereby highlighting fruitful lines for further analysis. The paper thematically explores three distinct strands of the sociological literature. Firstly, a concern with local meanings, cultures and identities; second, the importance of leadership, co-optation and control; and thirdly, the critical importance of framing and the mobilising of an 'evidence' discourse to strategies of change. The paper encourages us to challenge the taken for granted assumptions of the dominant studies and their underpinning normativity. The authors highlight that service change is complex, 
contested and operates across a diversity of levels. The multifactorial nature of such changes negates normative, evaluative studies. Ultimately, more voices need to be heard and researchers should be asking more critical questions and drawing on more diverse theoretically and sociologically informed approaches if we are to progress understanding in this area.

Next, we turn to Lorne et al - 'Regional assemblage and the spatial reorganisation of health and social care: the case of devolution in Greater Manchester, England'. This paper is focused at the macro-/meso-level and draws on empirical data taken from an ethnographic study of the Greater Manchester devolution reforms with fieldwork undertaken from 201517. These reforms had high political visibility and affected over $2,700,000$ people. The study draws on documentary review, extensive observations and semi-structured interviews with key stakeholders. The paper explores the dynamic processes through which space is socially produced. The authors link this insight to the concept of 'assemblage' (Deleuze and Guattari, 1988) and the ambiguity and fragility of the new alliances and understandings required to 're-make' the region as a spatial entity. The use of assemblage is a helpful way to unpick agency and structure within and across these various new alliances - allowing for a more nuanced relational understanding of 'leadership'. The paper explores the role of power, social practice and contingency in these interactions. The findings centre on firstly, the internal construction of a 'Greater Manchester' identity; and secondly, the external projection of this 'Greater Manchester' identity - and the pressures, tensions and contradictions linked to both these spatial practices. The paper encourages us to consider the social, political and power dimensions of 're-making' a region through service change in 
health and social care. In this way, it makes a case for evaluation to eschew the traditional 'before-after' concerns, or the commonplace work around 'theory-of-change' modelling and instead reminds us that conflict and political contestation are important research concerns through which we may learn a great deal.

The third paper in this special section is 'A sociology of public responses to hospital change and closure' by Ellen Stewart which explores case studies of three sites in Scotland undergoing service changes. The focus of this study is at the meso- and micro-levels. Whilst Lorne et al canvassed practitioner perspectives; Stewart focuses firmly on members of the public - a group frequently marginalised in studies of service change in healthcare. In theoretical terms, the paper takes a fruitful dual approach drawing on sociological studies of 'what hospitals are' and social science research on 'publics' to explore the contested 'unmaking' of health care spaces and the different ways in which these processes are experienced by different people. The paper demonstrates that there are multiple meanings and interpretations of what hospitals are for different communities and these change over time. The meanings that publics attach to hospitals may often clash with the meanings and understandings that managers have. It is also the case that publics are heterogeneous. Importantly, the paper demonstrates that service change is a social phenomenon rather than merely a policy problem as frequently portrayed in the more normative literature. The paper generates some significant further points. Firstly, if neither publics, nor hospitals can be self-evidently understood - but are conversely emergent, subjective and multiple - then standardised public engagement practices around service change (and hospital closures) ought to be reconsidered. Secondly, and connected to this - engagement with publics 
requires time and deep attention to lived experience - this may run counter to the ethos of standard consultation practice. Thirdly, the managerial fixation on clinical services in relation to service change, misses the implications of the prior two points. In this way, the paper highlights how a sociologically informed analysis of service change may offer important learning beyond academic circles.

The final paper in this collection is "From "holding pen" to "a space to breathe": affective landscapes in a newly-integrated sexual health clinic' by Sarah Wright. This ethnographic study examines change at the micro-level, and focuses entirely on patient experiences of changed services. The paper follows patients through a series of spaces in a newly reconfigured 'one stop shop' integrated sexual and reproductive healthcare facility in Scotland. The paper draws on affect theory and combines this with a consideration of 'therapeutic landscapes' to consider 'affective landscapes'. The paper commences with an exploration of the space in which patients first arrive - the 'holding pen' and explores some of the negative experiences this space fosters alongside a sense of internalised shame. Next the paper takes us through the main waiting room following admission, and finally across the threshold and into the atrium which offers a much more positive space - 'a space to breathe'. The paper highlights the affective power of this space on patients - challenging prior assumptions and sensations of stigma. The paper (following Stewart) once again juxtaposes the concerns of managers and policy makers - whilst 'integration of services' is a key political and policy objective, Wright demonstrates that this is of little concern to these patients. More important is the internalised experiences of these individuals and how these can be influenced by spatial manifestations. Once more echoing Stewart's contribution, she 
orients us towards the complexity of the patient experience and understanding and its incompatibility with managerial concerns for metrics and measurement. The paper articulates the voices and experiences of a group of patients who are frequently marginalised. It challenges us to think more deeply about the relationships between notions of integration, spatial distribution of healthcare facilities and how changes in these services impact upon the experiences of patients.

\section{Emergent themes and final reflections}

Reading across these four papers, we find three themes worthy of further reflection.

Firstly, the sociologically informed approach they share ensures they all problematize the role of power in service change. This is significant - as Jones et al demonstrate - this has not always been the case in studies of service change. The papers are cognizant of the 'spatial turn' in social sciences (Thrift, 2006) but they focus especially on the relationships between power, space, politics and dominant (often managerial) discourses. They highlight the power implications of un-making and re-making space and draw our attention to which actors do this and through which organising rationalities. In a managerial context in which measurement is of primordial importance - these papers challenge us to consider the countervailing importance of what cannot be so easily measured - for instance 'presence', 'belonging', and 'community' or a sense of what is 'ours', and 'who we are' . In this way the papers encourage us to widen the lens when researching service change from a focus on what can be measured, ranked or evaluated, to what can be experienced, and how it can be experienced. 
Secondly, the papers highlight the importance and the social nature of the relationships between different stakeholders and emphasise that these are not incidental to service change but integral to it. The ongoing importance of structural dimensions of relational power between professionals, managers and patients/publics identified by Alford (1975) in his seminal work on service change resonates here. It is notable that the importance of conflict between actors - and the fact that this can be productive, challenges the dominant management ideology to minimise this. These papers - particularly those by Stewart and Wright - also highlight how service change impacts upon the relationships that patients have with the spaces within which they receive their care - once more reiterating the much ignored spatial elements of health care, encourages deeper thought around issues such as 'ownership' and 'stigma'.

Thirdly, and linking the two prior themes - these papers emphasise the importance of considering multiple views and multiple voices in studies of service change. A sociological approach refuses to prioritise dominant voices over others, but instead offers space for views and voices that are often not encountered. Stewart's description of 'recurring threat' of hospital closure experienced by public stakeholders also orients our focus to the temporal and historical nature of service change and how a sense of place is intertwined with feelings and emotions. 
All these papers highlight the multiplicity of voices and views that augment understandings about the environments in which we live and the roles played by healthcare services therein. Ultimately, it is through this richer understanding of factors that are frequently dismissed, intentionally marginalised or simply ignored that a sociological approach to service change delivers its critical contribution.

\section{References}

Alford, R. R. (1975). Health care politics: Ideological and interest group barriers to reform Chicago: University of Chicago Press.

Callon, M. (1986). Some elements of a sociology of translation: domestication of the scallops and the fisherman of St Brieuc bay. In Law, J., editor, Power, action and belief: a new sociology of knowledge, London: Routledge, 196-232.

Colson, E. (1971). The social consequences of resettlement: The impact of the Kariba resettlement upon the Gwembe Tonga (No. 4). Manchester University Press.

Dean, M. (2010) Governmentality: power and rule in modern society, (Second Edition) Sage, London

Deleuze, G., \& Guattari, F. (1988). A thousand plateaus: Capitalism and schizophrenia. Bloomsbury Publishing.

Foucault, M. (2007) Security, territory, population: lectures at the college de France 1977-78, edited by Senellart, M. Palgrave Macmillan, New York 
Fulop, N., Walters, R., \& Spurgeon, P. (2012). Implementing changes to hospital services: Factors influencing the process and 'results' of reconfiguration. Health policy, 104(2), 128135.

Jensen, C. B. (2008). Sociology, systems and (patient) safety: knowledge translations in healthcare policy. Sociology of health \& illness, 30(2), 309-324.

Jones, L; (2016) Policy as discursive practice: an ethnographic study of hospital planning in England. PhD thesis, London School of Hygiene \& Tropical Medicine Jones, L., \& Exworthy, M. (2015). Framing in policy processes: A case study from hospital planning in the National Health Service in England. Social Science \& Medicine, 124, 196-204. Jones, L. Fraser, A. \& Stewart, E. (under review) Exploring the neglected and hidden dimensions of large-scale changes to healthcare Sociology of health \& illness.

Legg, S. (2005) Foucault's Population Geographies: Classifications, Biopolitics and Governmental Spaces. Population, Space \& Place 11, 137-156.

Lemke, T. (2011). Biopolitics: An advanced introduction. NYU Press. New York. Lorne, C., McDonald, R., Walshe, K., \& Coleman, A. (2019). Regional assemblage and the spatial reorganisation of health and care: the case of devolution in Greater Manchester, England. Sociology of health \& illness.

Pettigrew, A., Ferlie, E., \& McKee, L. (1992). Shaping strategic change-The case of the NHS in the 1980s. Public Money \& Management, 12(3), 27-31.

Thrift, N, (2006), Space, Theory, Culture and Society 23, 2-3, 139-46

Stewart, E. (2016) Publics and Their Health Systems. Palgrave Macmillan UK 
Stewart, E. (2019) A sociology of public responses to hospital change and closure. Sociology of health \& illness.

Wright, S. (2019). From 'holding pen'to 'a space to breathe': affective landscapes in a newlyintegrated sexual health clinic. Sociology of health \& illness. 